\title{
2
}

\section{Um appello em favor da amnistia}

Foi enviada ao Congresso Nacional em 1929 esta representação assignada por numerosos lentes da Faculdade de Direito de S. Paulo, pedindo a adopção da amnistia, em favor dos condemnados politicos:

Os abaixo assignados, cidadãos brasileiros no goso de seus direitos civis e politicos, comparecem perante vs. exas. para, usando do direito de representação que lhes outorga o artigo 72 paragrapho 9 da Constituição Federal, pedir seja decretada a mais ampla (geral, plena e absoluta) amnistia dos condemnados politicos, quer presos em prisões do Estado, quer ausentes em paiz estrangeiro. Começarão por fixar bem o caracter desta representação, e explicar o motivo de sua attitude, ou melhor, a opportunidade de ser debatida a questão tantas vezes agitada na imprensa e na tribuna, qual a da pacificação definitiva do Brasil, findo como se acha o processo a que foram submettidos os revolucionarios brasileiros.

Tratemos de um preliminar. Explica OrLando, no seu pequeno compedio de Direito Constitucional, que por duas 
phases passou o direito de petição e representação, que foi garantido pelo paragrapho 9 do artigo 72 da Constituição Brasileira : em sua origem o direito de petição na Inglaterra, era consequencia das funcções jurisdiccionaes do parlamento, de modo que tinha o caracter de uma verdadeira acção; em seguida teve o caracter de reclamação de uma reforma legislativa, e foi uma consequencia do direito de liberdade individual. (Principii di Dir. Cost. n. 407, Cooley, Dir. Const. pag. 312). Mas é de accentuar que nem sempre ha um pedido de reforma nas leis, mas sómente exposição do estado das coisas na sociedade, deixando os signatarios ao criterio da autoridade as medidas a serem adoptadas, e assim diz com razão Joaquim Gonzalez (Manual, n. 198) que é então a "faculdade que tem qualquer cidadão de dirigir-se aos poderes publicos, ás autoridades constitucionaes, para lhes dar a conhecer tal ou tal facto, tal ou tal estado de coisas, e reclamar-lhes a intervenção". E' este precisamente o nosso intuito. Mantendo-nos no seio do povo, conhecedores do estado de espirito dos nossos concidadãos, vamos mostrar nenhum perigo haver para a paz publica na concessão de ampla amnistia aos condemnados por crimes politicos. Não se nos objecte que as autoridades, particularmente os mais altos funccionarios estão mais informados do que nós do estado do espirito publico. Contestamos seja isto exacto. Só pela policia e pela imprensa recebe o Poder Executivo suas informações, e forma seu juizo sobre o estado do espirito publico. Ora, a policia, como está officialmente reconhecido, exaggera, não raro, e mesmo é illudida, tendo muitas vezes sido levada a affirmar revoltas e crimes contra os altos poderes do Estado, quando ninguem cogitou de se levantar contra a ordem constituida, e quando reina a mais perfeita concordia no seio da sociedade. A imprensa está fatigada de tratar do assumpto, e teme mesmo enfadar seus leitores. Além disto, não tendo a ultima mensagem presidencial feito a mais leve referencia a estes nossos concidadãos que jazem nos carceres de Estado, nem aos que longe da patria sonham com o dia em que 
tornarão a ver amigos e parentes, teve como consequencia distrahir o espirito publico (hoje tão entretido com a successão do presidente), desse problema tremendo, problema de cuja solução depende a felicidade da familia brasileira.

Houve quem asseverasse, pela imprensa diaria, que, sendo excepção estabelecida pela Constituição Brasileira a da concessão da amnistia pelo Poder Legislativo, não deveria o Congresso deixar de attender ao que fosse informado pelo Executivo. Ora, não ha verdade nem nas premissas, nem na conclusão.

O nosso constitucionalista Araujo Castro assim se exprime: "Nas monarchias, a amnistia é quasi sempre concedida pelos reis ou imperadores; nas republicas semelhante attribuição é conferida ao Legislativo, que é o poder que mais genuinamente representa a vontade popular. "Vae mesmo além e ensina que, quando concede o Legislativo amnistia, "nenhum dos outros ramos do poder publico tem autoridade para entrar na apreciação da justiça ou conveniencia da lei promulgada (pag. 105). "O grande Black explica que, mesmo na Inglaterra, o parlamento, no tempo em que, lentamente, firmou sua autoridade, sempre lutou para que lhe fosse reconhecida essa attribuição, e mostra que, sendo uma medida de caracter geral, é das de natureza a serem confiadas ao Poder Legislativo (Const. Law, n. ${ }^{\circ}$ 126). Em França, só por delegação do parlamento poderá o Executivo conceder amnistia (Burgess II/301, Dalloz, Amnistie, ns. 6 a 8). Mostra José Carrasco que, até mesmo em varias monarchias, é a concessão da amnistia materia da competencia da assembléa legislativa (Estudos, pags. 403 e segts.). Mas, quando assim não fosse, quando fosse uma originalidade de nossa Constituição conferir ao Congresso a faculdade de dar amnistia, falsa é a conclusão da mencionada imprensa, e zeloso deverá ser o Poder Legislativo em man- 
ter essa sua attribuição só recebendo do Executivo as informações que lhe parecerão de molde a esclarecel-o sobre a conveniencia ou opportunidade da medida: estamos certos de que assim procederá. Estranho parecerá que alguns cidadãos, sem o menor interesse pessoal, e somente animados pelo desejo de ver feliz a patria, venham representar ao Congresso sobre a necessidade dessa medida que, se é de clemencia, como tantas vezes se tem repetido, é tambem muito accentuadamente de politica, de conveniencia social. Marnoco E Souza dá a amnistia como sendo uma medida politica, tomada com o fim de apaziguar paixões (Const. n. 192). José Carrasco vae mais longe, porquanto ensina positivamente que a amnistia não é um acto de demencia, é uma medida politica" (Estudos, pag. 405). Ainda os mestres que admittem seja originada na clemencia lhe attribuem importantes effeitos politicos. Diz Roldan (Der. Const., pag. 204) que a imprensa diaria tem tornado quasi esquecido o direito de representação para outros fins a não ser o interesse dos que exercem esse direito. Mas já fizemos ver acima considerar a imprensa uma questão sem nenhum interesse para discussão a da amnistia, e teme enfadar seus leitores, de maneira que só fugidiamente, como fez o "Estado de São Paulo", em uma nota de duas linhas, insiste em que, antes de ser outorgada pelo Congresso, não está terminado o lamentavel incidente que, nestes ultimos annos, ensanguentou e enlutou a nossa patria.

Feitas estas observações preliminares ao intento de bem frisar o caracter em que nos apresentamos ao Congresso Legislatrvo, patenteado que nenhum outro interesse nos move que o da paz no seio da familia brasileira, entraremos no estudo da opportunidade da concessão da amnistia. Repete-se que é medida de clemencia, tanto mais aconselhavel quanto é certo que o crime politico, muito diverso do commum, nunca passa de um erro. Sim: é acto de clemencia dos irmãos victoriosos em relação áquelles que em um momento de desvario, menos bem apreciaram os actos das autoridades constituidas, mas é muito mais proveitosa pelo 
que de politico tem, obrigando os revoltosos a uma gratidão para com os que foram generosos no julgamento de sua acção, por vezes sanguinosa e sempre tremenda, como é precisa para o exercicio do direito de revolução.

Verdadeiramente só uma objecção séria se levantou contra a concessão da amnistia, e vem a ser a de não se acharem ainda inteiramente pacificados os espiritos, ainda hoje agitados pelos actos e pelas proclamações dos revolucionarios. Mas, embora entendamos que houve sempre exaggero, senão falsidade, nesta affirmação, podemos assegurar que tudo indica uma completa paz de espirito, só mareada pela dor sentida pelos amigos e parentes dos condemnados que gemem nas prisões, ou que, longe da patria, soffrem as agruras do banimento.

Factos eloquentes provam a these que acabamos de emittir. Podemos apresentar a formação de um partido legal de opposição, que attrahiu para o seu seio, que internou em seu gremio, um elevado numero de revolucionarios. E' o reconhecimento por estes elementos de que, pelos meios legaes, pelas urnas, pela imprensa, pela tribuna, pelos outros processos permittidos e reconhecidos por nossas leis, todos os males de que se queixa o povo podem ser combatidos. Em segundo logar, podemos citar o facto da discussão ardente sobre qual o candidato preferivel para occupar a cadeira presidencial. Se o povo tão interessado se mostra por esta successão é que seguramente espera que o novo presidente occupará de facto a cadeira suprema, e que nenhuma revolução poderá surgir que torne inutil o actual cuidado na escolha do chefe a quem 
será dado dirigir os destinos da patria. Podemos, em terceiro logar, apontar a propria mensagem presidencial que é muda sobre o assumpto. Signal é o calar-se, a tal proposito, o presidente de que considera uma questão morta a da transformação da ordem politica da patria pelas armas. Um outro symptoma desse socego está em durante um já longo espaço de tempo, não terem sido denunciados movimentos de rebeldia contra a actual ordem de coisas.

Nem poderia ser de maneira differente, uma vez que o Poder Executivo tem declarado por mensagens, pela imprensa official e por outros modos, que a regularisação da sahida do café, as tarifas protectoras da industria nacional e a estabilisação deram nunca vista prosperidade á agricultura, á industria fabril e ao commercio. Sendo certo que o factor economico de nenhum modo pode ser considerado unico gerador ou determinador das vicissitudes sociaes, é indubitavelmente o mais importante, e por isto mesmo, não se póde negar fé á these proclamada por Tocoueville e por outros sociologos de menor nota, qual a de serem as revoluções quasi sempre nascidas da miseria popular.

Mas passam os abaixo assignados a considerar o acto dos revolucionarios pelo aspecto juridico, dando a maior attenção á maneira por que foram condemnados á prisão e ao banimento. Ao tempo em que explodiu a revolução era o crime da alçada do jury. Veiu uma lei posterior que o submetteu ao julgamento do juizo togado (L. 4.848 de 13 de Agosto de 1924, arts. 1, 2 e 10). Ora, parece aos abaixo assignados, cidadãos no direito de vêr cumpridas as promessas constitucionaes, que não podiam ser tirado da competencia do jury taes processos, porque o art. 72, paragrapho 31 , não póde deixar de ser o compromisso solemne de que nenhum dos crimes da competencia do jury poderá passar a ser julgado por outro juizo. O contrario 
seria autorisar o legislador ordinario a privar o jury de quasi todas as suas attribuições, como aliás se fez na Justiça Federal, tornando-o um verdadeiro fossil, e desrespeitando-se dest'arte o art. 72, paragrapho 31 da Constituição. BarbalHo, pelo que se lê ás pags. 337 e 338, só admittia houvesse modificações em pontos não essenciaes do tribunal popular: não era partidario de se lhe restringirem as attribuições para "abolir-se, sob disfarce, uma garantia constitucional".

Ainda mesmo os inimigos da instituição, que formaram escola aqui, na Italia, na Hespanha e em Portugal, deverão reconhecer que antes de desapparecer a promessa do art. 72, $\S 31$ do corpo de nossa Constituição, força é reconhecer que á lei ordinaria supra-citada deve ser negada applicação pelos tribunaes brasileiros por ser inconstitucional, e portanto dever ser considerada não escripta, sem existencia entre as leis patrias.

Dado porém seja ella constitucional, como negar-lhe a inapplicabilidade a actos occorridos antes de sua promulgacão Poucas vezes têm os abaixo assignados encontrado mais flagrante violação da letra do art. 72, paragrapho 15 da Constituição Federal do que no caso da sujeição dos revolucionarios á lei de Agosto de 1924 por actos praticados em Julho do mesmo anno!.

Não param aqui as queixas que têm os cidadãos infra-assignados contra o modo por que foram tratados os revolucionarios, com desrespeito, em seu modesto sentir, da letra constitucional, visto como ainda houve a decretação da imprescriptibilidade dos delictos politicos (art. 12), o que vale o mesmo que o restabelecimento do banimento para taes delictos, contra o firmado no art. 72, paragrapho 20 da Constituição Federal. Se ficaram os revolucionarios que se encontram no estrangeiro nas mesmas condições 
fixadas pelo art. 46 do Codigo Penal de 1890 a que se referiu a Constituição de 1891, é claro que estão precisamente no estado a que fez allusão a letra constitucional: "Actus non a nomine, sed ab effectu judicatur" Se se indagar qual o motivo da abolição do banimento nas leis modernas, facil será encontral-o Sabido é que foi elle applicado particularmente aos delictos politicos. Considerando porém os jurisconsultos que as perseguições politicas e religiosas tinham privado as communhões sociaes em que havia a intolerancia religiosa e o despotismo politico de elementos importantissimos, talentos de escol, individuos dotados de rara energia, como succedeu a Portugal, nos seculos XVII e XVIII, entenderam ser de conveniencia social impedir que nos momentos de exacerbação, supersticiosa ou despotica, se désse a sahida, pelo banimento de homens utilissimos ao paiz.

Disse, ha pouco, o Poder Executivo, manifestando-se contra a amnistia, que estava a organisar um exercito disciplinado, ordeiro, pacifico, incapaz de rebeldias. Temos 0 direito de perguntar se será tal exercito mais util á patria do que foi o de Benjamin Constant, Deodoro da Fonseca e dos que proclamaram a republica em 1889. Desordeiros sublimes os militares de 1889, e rebeldes indignos de pisar o solo da patria os de 1924!. Esta consideração nos leva ao estudo dos moveis que arrastaram os revolucionarios a, em Julho de 1924, dizer um ultimo adeus á familia, correr para as trincheiras, e expor-se somnolentos, esfaimados e sedentos ao fogo das baterias do governo. Como se sabe, sem que entremos no exame do processo a que responderam elles, tres eram seus capitulos de accusação contra $o$ governo do presidente Bernardes: as cartas que mareavam a reputação do exercito, o filhotismo e a humilhação que nos foi infligida pela missão ingleza. Ora poderá haver erro da parte dos militares: bem podiam ser falsas as car- 
tas, não haver uma oligarchia insupportavel no Brasil e ter sido por elles mal interpretada a interferencia da missão ingleza em nossa vida economica. O que é certo porém é que elles não se mostraram homens perigosos para a patria, mas viris na sua reacção contra males reaes ou imaginarios. Podem ter errado, mas não podem ser havidos como sendo membros gangrenados de nossa communhão social. A não ser embellecados por um nobre ideal, não se expõem os homens ą serem despedaçados ou queimados pelas armas certeiras e poderosas contra elles apparelhadas. Não foram por sentimentos baixos arrastados os revolucionarios para as trincheiras em que perdiam a vida, famelicos, sequiosos, trabalhados de somno e de frio e com as vestes despedaçadas.

Reatando, porém, o fio de nossa exposição, diremos crer serem merecedores de abrogação os preceitos legaes que de.cretaram a deslocação de delictos politicos do jury para o tribunal togado, e que infligiram aos criminosos politicos que se retiram para o estrangeiro a pena de banimento, por assim dizer, automaticamente applicada. Antes que essa providencia seja tomada, cumpre que uma amnistia acuda immediatamente aos aggravos que, falando com o mais profundo respeito, têm sido feitos aos nossos patricios que foram privados das doçuras do lar.

Antes de passarmos ao estudo das vantagens da amnistia, de sua feição politica e pacificadora, seja-nos licito responder a um argumento que tem sido apresentado ás massas menos cultas e que seguramente a certos homens que não conhecem as condições de desenvolvimento social se afigura como procedente. Referimo-nos aos males materiaes da revolução. Mas, dignissimos senhores Represen- 
tantes da Nação Brasileira, todos sabemos, desde que tenhamos alguma cultura, que o progresso social não se pode fazer senão com intervallos de luta, mesmo sangrenta. Ai do paiz em que o exercito fosse incapaz de enfrentar o inimigo mostrando-se afeminado e sentimental: Nas lutas entre compatriotas ou com o estrangeiro, nada mais ha a exigir, pelos principios do Direito das Gentes, do que um minimo de violencias, e. neste particular, foram inexcediveis os revolucionarios de 1924, como testemunharam os paulistas e a imprensa independente.

Será porém a amnistia, como affirmam os temerosos, uma imprudencia, trazendo para o seio da patria homens que amanhã retomarão as armas, ou, ao contrario, dará penhor de que esses patriotas que arriscaram a vida em 1924 serão gratos á magnanimidade dos Representantes do povo brasileiro, e voltarão aos seus lares desejosos de viver e morrer em paz? Responderá por nós essa mestra da vida que é a Historia. Se raras são as leis que podemos ter em Historia, ao contrario do que sustenta LAcombe (De l'Histoire considerée comme Science, C. I. pag. 3 i f.), uma dellas é seguramente a de que as amnistias amplas, plenas, absolutas têm tido sempre como consequencia a pacificação dos espiritos, e que se lhes segue fatalmente um periodo de calma social. Mougeolle (Problemas da Historia) e LitTrÉ (Do Positivismo) ensinam que os nossos raciocinios e nossas conclusões tiradas a "priori" encontram seu correctivo, sua emenda, sua contraprova ou sua confirmação nos factos ou na realidade de que nos dá conta a Historia. Fique porém bem accentuado que a amnistia só tem essa virtude sendo completa e absoluta. Se tem de ser concedida uma amnistia parcial, condicional, restricta, 
melhor é em nosso desautorisado modo de sentir, firmado no dos grandes historiadores, que não seja ella concedida: será uma fonte de discordias e perseguições como têm sido todas as que não foram dadas com a maior amplitude. $\mathrm{Na}$ excellente obra de Carrasco, Estudios, encontramos noticia de muitas amnistias, classificando-as elle em amplas ou absolutas e restrictas, e dando, destas, duas sub-classes, a das parciaes e a das condicionaes (Estudios, pag. 401). Pela lista dellas e pelos conhecimentos que se tenha de Historia, facil será reconhecer a verdade da these acima emittida; salutares as amnistias amplas, completas, sem restricções; maleficas, as outras. No Direito, vol. 84, pags. 161 e segts., está uma dissertação offerecida á Faculdade de Direito de São Paulo, pelo Dr. Camara Leal, em que elle desenvolve precisamente a mesma these, referindo as mais notaveis amnistias, a partir da concedida por Thrasybulo, 404 annos antes de Christo, a qual é tida como sendo a mais antiga de que dá noticia a Historia. Na ultima parte de sua dissertação, estuda a amnistia em face dos principios philosophicos, e termina o seu ensaio affirmando que "a amnistia deve ser geral e absoluta", porque só assim dará a pacificação dos espiritos.

Dentre os signatarios desta representação, alguns ha que ficaram dentro da Capital do Estado de São Paulo nos lutuosos dias de Julho de 1924. Sabem o que é passar quasi um mez sob a pontaria de dezenas de canhões que bombardeavam esta cidade. Ouviram o rugido das granadas mortiferas, destruindo os edificios e espalhando a morte, do mesmo modo que tiveram a triste musica das balas que silvavam, deixando mortos seus companheiros de infortunio. Foram testemunhas dos crepitantes incendios que provinham 
dos projecteis inflammaveis lançados pela artilharia e pelos aeroplanos.

Viram operar os tanques, pisando combatentes malferidos e moribundos, machinas que fazem lembrar os antigos carros de guerra, por Homero comparados aos instrumentos agricolas com que o lavrador rasga a terra e esmaga as céspedes. Assistiram á scena tremenda que houve na noite em que o ministro da Guerra lançou uma proclamação ordenando que todos os habitantes desta Capital se retirassem, para que elle agisse livremente contra os revolucionarios, proclamação tanto mais terrivel quanto era vaga. Mulheres, crianças, velhos tropegos e já na decrepitude, muitas dessas pessoas soluçando e debulhadas em lagrimas, perguntavam o que lhes era ainda reservado, além do que tinham já soffrido, se seria incendiada a cidade, ou se seriam seus habitantes asphyxiados pelos gazes venenosos que o governo já encommendára, e, espavoridos, indagavam para onde fugir, sem dinheiro, sem meios de transporte, sem alimentos, em quadra tão sinistra. Para muitos vinham á memoria as descripções da ultima noite de Troia, na Eneida de Virgilio, ou do incendio de Moscou, devido á penna de Sir Archibaldo Alison. Bem se lembram essas testemunhas de tão lugubres scenas da alegria que tiveram, quando, na madrugada da sahida dos revolucionarios, bimbalharam em repiques festivos os sinos do mosteiro de São Bento, annunciando o restabelecimento da paz; já não os impressionava o trom da artilharia que continuou, por muitas horas, a lançar ferro e fogo sobre a nossa bella Capital. São pois incapazes, testemunhas dos horrores da revolução de Julho de 1924, sem embargo de toda a moderação dos revoltosos, de pedir para estes a amnistia, sem a certeza de que será ella o mais completo remate da pacificação dos espiritos, restituidos ás suas familias aquelles que, naturalmente por excesso de patriotismo, recorreram aos tremendos processos revolucionarios com o intento de beneficiar e servir a patria. 
P. P. deferimento, certos, como estão, pelos amplos debates, da conveniencia da medida, que, desde muito, julgam, deveria ter sido adoptada.

São Paulo, 26 de Junho de 1929.

João Arruda

Waldemar Ferreira

José Ulpiano

Octavio Mendes

Vicente Ráo

Gama Cerqueira

M. Pacheco Prates

Mario Masagão

Theophilo B. de Sousa Carvalho

Braz de Souza Arruda

M. F. Pinto Pereira

Lino de Moraes Leme

Laurentino de Azevedo

Antonio Ferreira de Almeida Junior 